\title{
DETERMINATION OF THE OPTIMUM MATURITY OF NEW RICE FOR AFRICA USING ARTIFICIAL NEURAL
} NETWORK

\author{
Peter, A. \\ Department of Mathematical Sciences, Kaduna State University, Kaduna, Nigeria \\ Corresponding Author's Email: ayubng@kasu.edu.ng
}

\begin{abstract}
The New Rice for Africa (NERICA) is a child birth of research to improve upon the production of rice in subSahara Africa due to challenges of shortages in agricultural food production. Two major varieties were obtained, for low lands and uplands. NERICA-4 is commonly suited for uplands and has delicious taste as compared to the other upland varieties. However, the problem of loss of grains at harvest which translates to low productivity amongst other factors needs to be addressed. In this paper, about $750 \mathrm{~m} 2$ farm land was cultivated with NERICA-4 rice variety and 60 images at different maturity period with ten features extracted, preprocessed and processed using MATLAB2018Ra software. The processed images were classified using Artificial Neural Network to determine the optimum maturity period based on visual properties. 93.30\% classification accuracy was obtained. This shows that when made operational, the loss of grains can be drastically reduced and productivity increased.
\end{abstract}

Keywords: Artificial Neural Network, Classification, NERICA-4

\section{INTRODUCTION}

The increase in population worldwide requires a corresponding increase in the production of food to support the growing population. Several efforts have been put in place by agricultural research institutions, governmental organizations, nongovernmental organizations, etc. in improving the yield of agricultural produce. These they have done by cultivating more land mass, controlling the problems of Insect pests, weeds, diseases, Vertebrate pests, Nematodes, etc. and equally improving on the soil fertility, reducing the acidity of the soil, mitigating the problems of soil erosion, etc. A more worrisome challenge is that of drought. Draught is one of the main limitations in the farming of rice. Rice usually requires high amount of rainfall distributed uniformly throughout the growing period. This is not achievable in most parts of sub-Sahara Africa, especially Nigeria. The impact of draught is much felt in the uplands than lowlands. Rice varieties for uplands should possess the resistance for draught.

Efforts are being made by government at all level in fighting the menace of draught by encouraging people to plant more trees. However, this is not sufficient as the rate of draught supersedes the rate at which trees are planted and grow. Agricultural research organizations all over the world are making efforts in combating the effects of draught on agricultural produce by improving upon agricultural seedlings of several crops. They achieve this by producing draught resistant varieties. In Africa, one such effort is seen on a variety of rice called New Rice for Africa (NERICA) that can be grown on the uplands. NERICA variety is specially adapted to uplands with minimum period of maturity ranging from less than 90 to 100 days. Famers of most agricultural produce in sub-Sahara Africa (SSA) usually allow their produce to reach biological maturity before harvesting. One of the challenges faced by farmers of NERICA rice variety is that of loss of the yield during harvest. This practice affects the quantity of crops that is usually obtained at harvest. Substantial amount of the yield from NERICA is lost at harvest. This amongst other reasons has also affected the recommendation to farmers in using the NERICA rice varieties in the uplands (Kamai, Omoigue, Kamara, \& Ekeleme, 2020; Of, Mu, \& Okeke, 2018). Though several famers have adopted the technique of early (before biological maturity) harvesting, this has resulted in the problem of harvesting premature grains with less weight and not easily threshed and sometimes remain on the panicle, thereby reducing the yield. In some cases, late harvesting is adopted by some farmers; this too results in the number of cracked grains being increased during milling, the problem of before harvest grain sprouting and birds' attacks on the rice also affects yield (Shinya, Kosaka, Inoue, Koimaru, \& Sokei, 2011). The problem of human eye weariness, differences in sight, and differences in perception still affects the exact period that NERICA is harvested (Peter, Abdulkadir, \& Abdulhamid, 2017). Determining the optimum maturity of NERICA-4 rice variety ranges from the end of the thirteen weeks after sowing to the fourteen week after sowing, which is usually experienced by change in color from yellow to golden (Shinya et al., 2011). In knowing the exact time for harvesting the grain by using human eyes is a herculean task due to the factors afore mention. 
In rice, the maturity varies from one variety to the other, especially when the numbers of days are used in the determination of each rice variety as temperature affects the maturity (Oli, 2018; Meena, Prasad, Dotaniya, \& Meena, 2014). However, when visual characteristics are utilized, the husk color plays an important role in determining the optimum maturity of each variety (Kamai et al., 2020; Food and Agricultural Organization of the United Nations (FAO), 2017). The husk color in NERICA-4 rice variety at optimum maturity is usually golden in color (Rodenburg et al., n.d.). In improving agricultural activities image processing (IP) techniques are utilized. The assessment of food value features is commonly done by IP methods that improve the independent and dependable measured outcomes. IP rely on the fact that the human spectrum receives visible light in the form of red, green, and blue (RGB) which are the color stimulus focal points. The classification of colors is commonly done using RGB and hue, saturated, and value (intensity) (HSV) color models. The RGB color model is represented by binary digits from 0 to 255 , while the HSV color model ranges from 0 to 1 . Millions of colors can be distinguished using RGB color model, however, it does not represent the way humans visualize colors. Any color model can be obtained from the other by transformation. It is more reliable to use the HSV color model in representing the way humans understand colors (Peter et al., 2017). IP techniques have the capability of converting images into picture elements (pixels) that are used as inputs in the artificial neural network (ANN). ANNs are electrical analogue of the brain, as it mimics the brain activities in all respect. The ability of ANN to exhibit knowledge discovery and adapt to changes gives it the capability to classify objects more accurate than most techniques (Peter, Damuut, \& Abdulkadir, 2020a). The rest of the paper is organized as follows: Section 2 is the presentation of materials and methods, Section 3 presents the results and discussion, and Section 4 concludes the paper.

\section{MATERIALS AND METHODS}

In this work, NERICA-4 rice variety, site selection for farming, preparation of land for cultivation, a digital camera FINEPIX Z35 Full High Definition Charge Couple Device (CCD), NERICA-4 images are the materials. The methods deployed are capturing of the images using the camera, image processing by converting the RGB image format to HSV image format, classifying the HSV image format using ANN Tool Box in MATLAB. The frame work of the system comprising of NERICA-4 cultivation, image acquisition, image processing, and image classifications is presented in Figure 1.

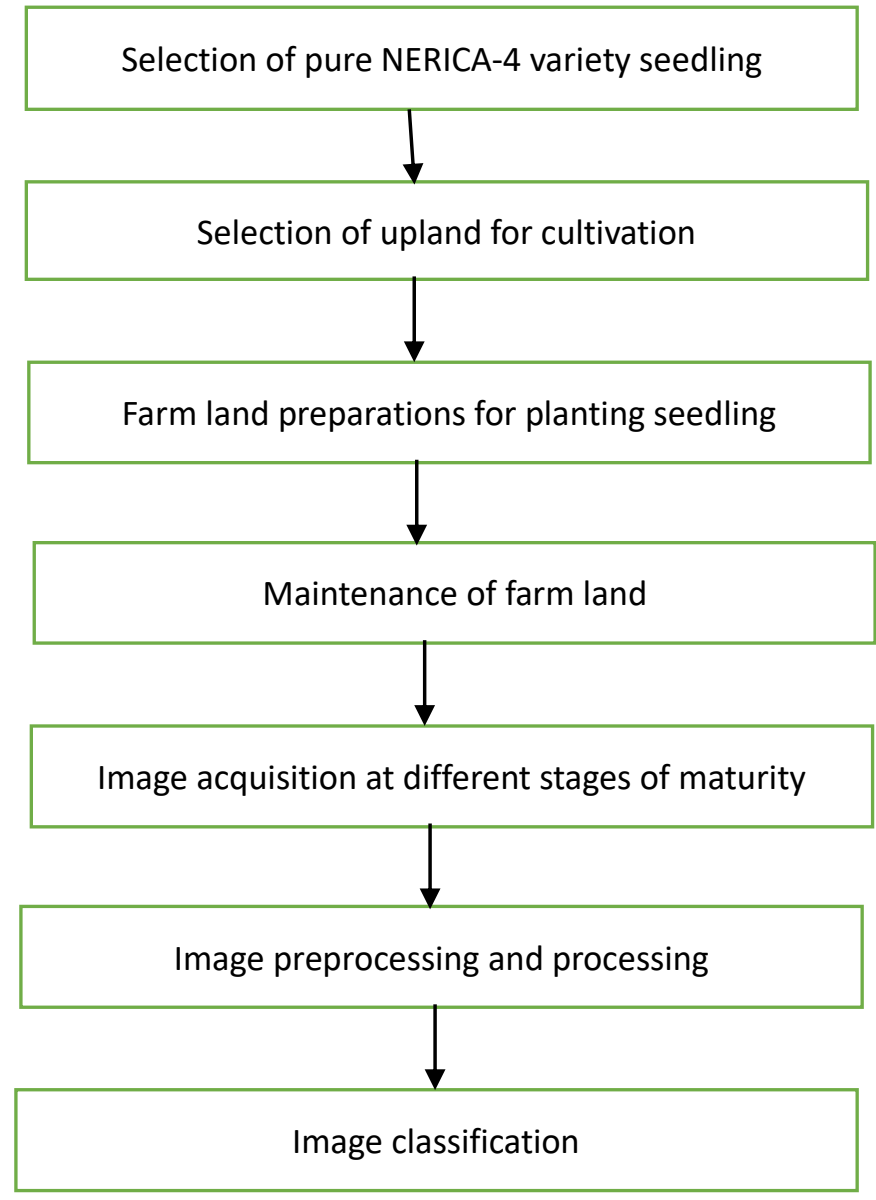

Figure 1: Frame Work of the System 


\section{NERICA-4 Rice Variety}

Rice plant (Oryza sativa L.) is a member of the grass family which is an essential staple food in the world. NERICA-4 rice variety obtained from the success in crossing Oryza sativa L. (Asian rice) having high yield capability and Oryza glaberrima Stued. (African rice) by the Africa Rice Center (AfricaRice) that is tolerant to drought and phosphorus deficiency, resist pests and cultivated throughout the sub-Sahara Africa (SSA) ecological region (Oikeh et al., n. d.; Shinya et al., 2011) is cultivated on a farm land in Kujama for the research purpose.

\section{Site Selection}

The site cultivated for the NERICA-4 rice variety is located in Pamfura-Kujama in Chikun Local Government Area of Kaduna State. The land has good drainage, water retention potential, with very good clay and organic matter. The site has at least 12$25 \mathrm{~mm}$ of rainfall during the farming season (Troldahl, 2018).

\section{Land Preparations}

The land is cultivated manually by leveling it using hoe. The land is expose to good amount of sunlight. The thick bushes were cleared and burnt, while the small debris and weeds were weeded and left to rot in the farmland as manure. The land is a size of about $750 \mathrm{~m}^{2}$ areas. The land preparation was done in February, 2020.

\section{NERICA-4 variety seed preparation}

Winnowing was used to separate between filled grains and empty grains. About 90 seeds were selected out of the filled grains to test the germination potency of the seedlings. It was observed that about 80 seeds germinated within 4 to 5 days.

\section{Seed planting}

When the rains became regular in the early month of June, 2020, the seeds were sown into a depth of 3-4 cm using the drilling method (Shinya et al., 2011).

\section{Initial Weeding}

In an effort to reduce competition for nutrients and sunlight by weeds, regular inspections of the rice plantation are done and weeded before the application of the first fertilizer. This ensured a sanitized field and equally kept rodents away.

\section{Basal Fertilizer}

Fifteen kilograms (15kg) of N P K (15: 15: 15) was applied around the third leaf development to ensure that there is no loss of fertilizer due to heavy rainfall. This helps to increase the number of tillers.

\section{Top Dressing}

At the seventh week, which is about fourty-five (Panicle initiation stage) days after sowing (DAS), $7 \mathrm{~kg}$ of Urea fertilizer was applied to increase the yield of the NERICA-4 rice variety. When the rice was about ten weeks that is about seventy-five (Meiotic stage) DAS, the second application of $5 \mathrm{~kg}$ Urea was done to increase the number of filled grains.

\section{Image Acquisition}

The Full High Definition CCD digital camera FINEPIX Z35 inclined at $90^{\circ}$ and 5 inches from the NERICA- 4 rice variety plant was used to capture sixty images each of the different maturity stages. The first stage of maturity was when the plant has attained the late dough stage around the end of eleventh weeks to the middle of twelve weeks after sowing. The second stage of maturity was when the plant is at the end of twelve weeks to the middle of thirteen weeks after sowing. The third stage, being the ripening stage was between the end of thirteen weeks to the end of fourteen weeks (Shinya et al., 2011). Figure 2 is the sample of the different maturity stages. 

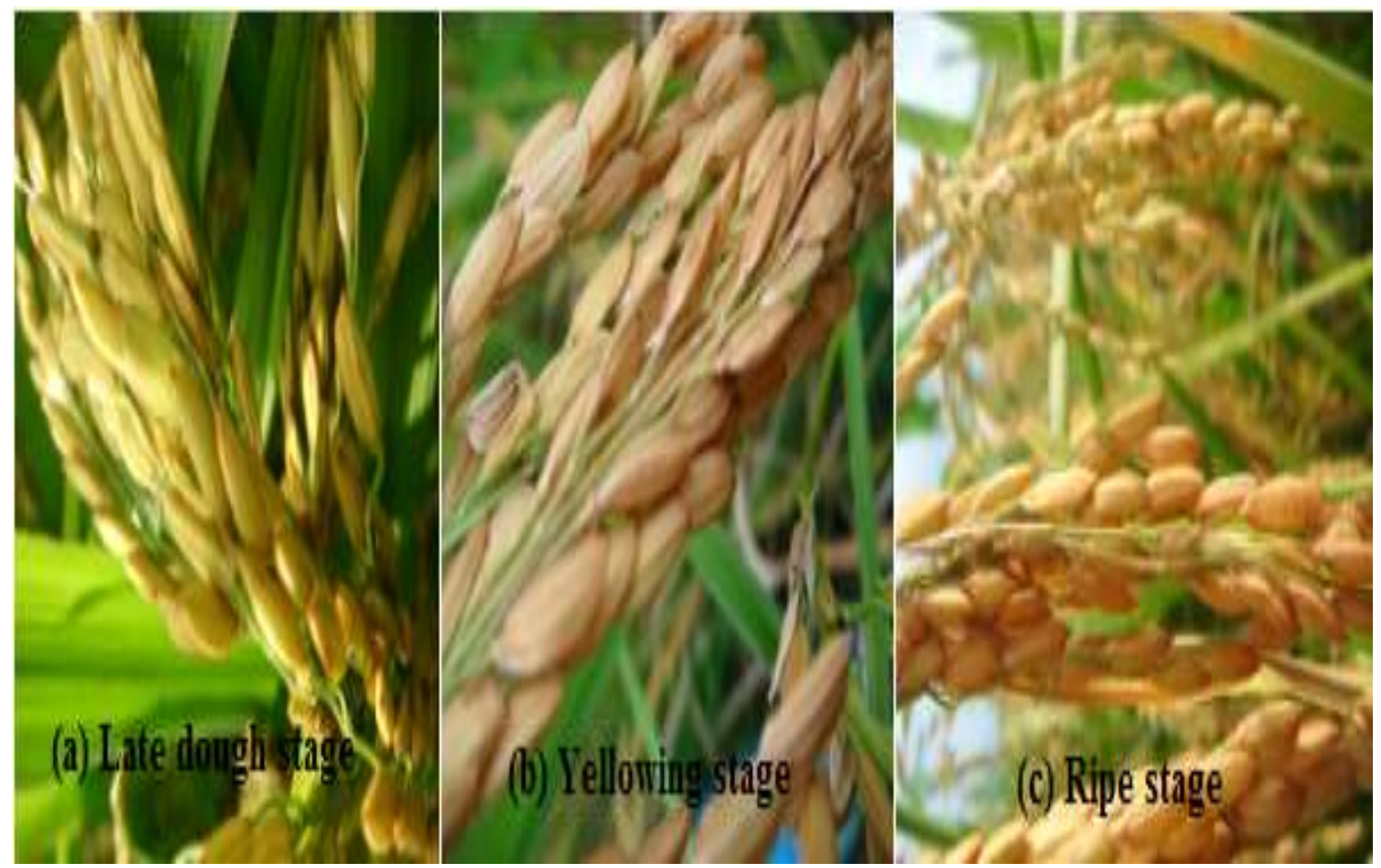

Figure 2: Different Maturity Stages

\section{Experimental Setup}

The image preprocessing, processing and classification are performed on a 64-bit Operating System Service Pack1 Windows 7 Ultimate. The processor is an Intel ${ }^{\circledR}$ Core (TM) i7, 2620M CPU@2.70 GHz. RAM size is 8.00GB with 500HDD. MATLAB2018Ra implemented the script and ANN Toolbox.

\section{Image Processing}

In order to ensure proper focusing of the area of interest on the images, paint brush software was used in rescaling the dimensions of the images as a means of preprocessing. The preprocessed images were then converted from RGB color format to HSV color format. This was done to enable the proper identification and usage of key features of the images. Random de-noising was applied to the images in order to maintain the key features after extraction of the key features of the HSV color format. This was achieved by the use of average filters in MATLAB2018Ra (Peter, Damuut, \& Abdulkadir, 2020b). In preserving the originality of each image from the maintained features, each image value (intensity) component was sharpened. These were later combined with the hue and saturated components of each image to realize the objective of the image processing. Color and texture features are applied on each image in order to maintain precision and identity of images for classification. Mean and standard deviation of the color feature are obtained. In the case of texture feature, statistical characteristics such as contrast, correlation, energy and homogeneity were obtained by using the gray level cooccurrence matrix from the HSV color format images. In total ten features are extracted which are mean and standard deviations of the color feature of each component of the HSV color format making six features, and the four statistical properties, contrast, correlation, energy and homogeneity of the texture feature. These ten features served as input to the ANN model.

\section{Image Classification}

The input to the ANN model is three set of 60 samples each of image processed NERICA-4 rice variety having ten features. The target class is 60 samples each having three features. The 60 input samples are divided into three parts of 42 samples being $70 \%$ for training, which enable the network to automatically adjust errors. 9 samples being $15 \%$ for validation which assesses the network generalization and stops the training process when no improvement is recorded. The remaining 9 samples being $15 \%$ for testing works independent of training data. It provides an independent judgment of the network during and after the training processes. The trainscg function was used in training the Neural Network (NN) that has the potential of updating weights and bias values in accordance to scaled conjugate gradient backpropagation algorithm which is stable in low memory situation. 15 hidden neurons are used as shown in Figure 3, the 
pattern recognition $\mathrm{NN}$ view.

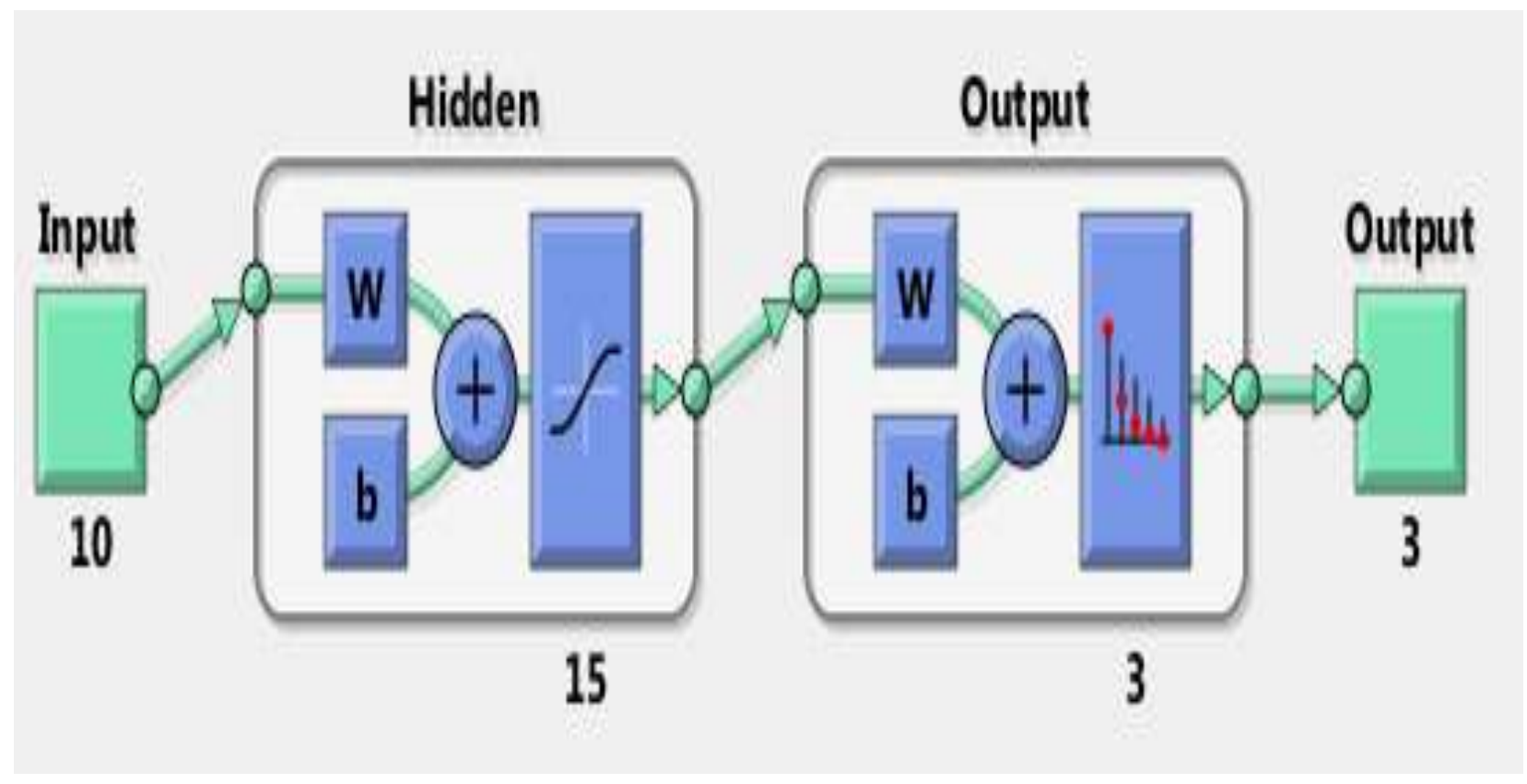

Figure 3: Pattern Recognition Neural Network view

Multilayer Feed Forward Neural Network and Activation Function

The ten features of each 60 samples are used as inputs to the feed forward neural network (FFNN) which are combined with their respective weights in the hidden layer with 15 hidden neurons as seen in Figure 3. In the hidden layer a bias weight is added to the sum of the product of the inputs and the weight. In the input units a linear activation function is assumed (see equation 1). However, in the hidden layer, a sigmoid activation function (see equation 2) is utilized in limiting the amplitude of the signal. The bias weight also delays the firing of the activation function, because the network weights would usually affect the firing of the activation function. The output from the hidden layer serves as inputs to the output layer. Each output signal combines with a corresponding weight at the output layer and the result is the three category classification of the network into late dough stage, yellowing stage and the ripe stage.

$y_{k}=\phi\left[\sum_{i=0}^{n} w_{k i} h_{i}\right]=\phi\left[\sum_{i=0}^{n} w_{k i} \phi^{h}\left(\sum_{j=0}^{m} w_{i j}^{h} x_{j}\right)\right]$

where $h_{0}=x_{0}=1, w_{k 0}$ and $w_{i 0}^{h}$ are biases, $y_{k}$ are the output nodes,

$w_{k i}$ areoutput weights, and $w_{i j}^{h}$ arehidden weights.

$\phi(x)=1 /\left(1+e^{-\lambda x}\right)$ 
where $x=\left(\sum_{j=0}^{m} w_{i j}^{h} x_{j}\right)$ in the hidden layer, $x=\left[\sum_{i=0}^{n} w_{k i} \phi^{h}\left(\sum_{j=0}^{m} w_{i j}^{h} x_{j}\right)\right]$ in the output layer and

\section{$\lambda$ controls the steepnessof the sigmoid function.}

\section{RESULTS AND DISCUSSION}

In this section, the results of classifications are presented in the form of confusion matrix, receiving operating characteristics, and network validation performance. Figure 4 is the confusion matrix giving the detail results of the classifications, Figure 5 is the receiving operating characteristics and Figure 6 is the network validation performance.
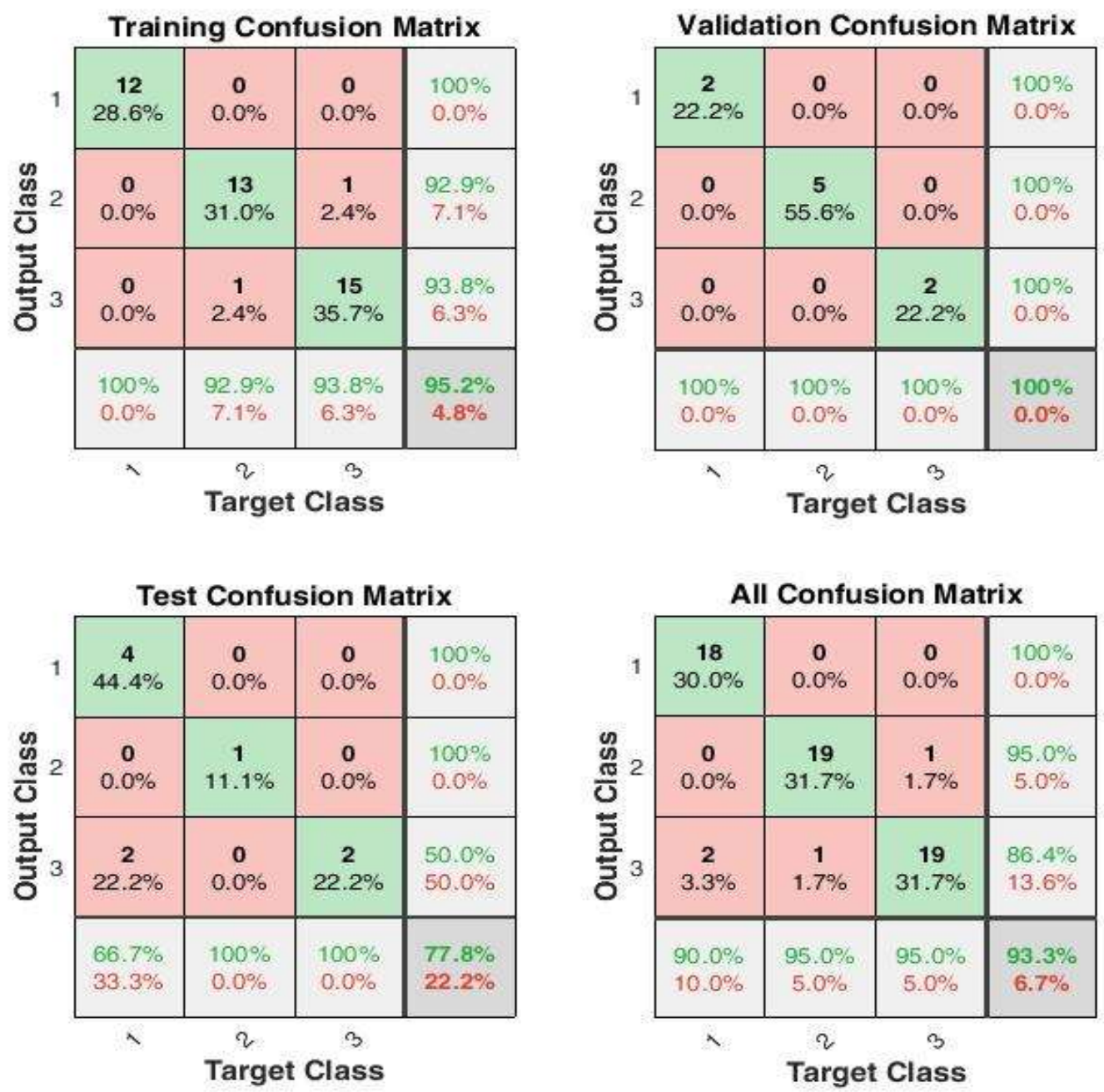

Figure 4: Confusion Matrix

In the training confusion matrix Figure 4, output classes 1, 2, for each class. This indicates the degree of precision of the and 3 gave a positive proportion of cases that are correctly classifier, which is a measure of how closely the predicted identify and classified as $100 \%, 92.9 \%$, and $93.8 \%$ respectively samples are agree with each other. The real fractions of positive 
cases identified correctly are equally $100 \%, 92.9 \%$, and $93.8 \%$ for target class 1,2 , and 3 respectively. This represents the sensitivity (recall). In the validation confusion matrix, output classes 1,2 , and 3 gave a precision of $100 \%$ for each class and a sensitivity of $100 \%$ for each target class too. In the test confusion matrix, the precision is $100 \%, 100 \%$, and $50 \%$ for the output classes 1,2 , and 3 ; and recall is $66.7 \%, 100 \%$, and $100 \%$ for the target classes 1,2 , and 3 .
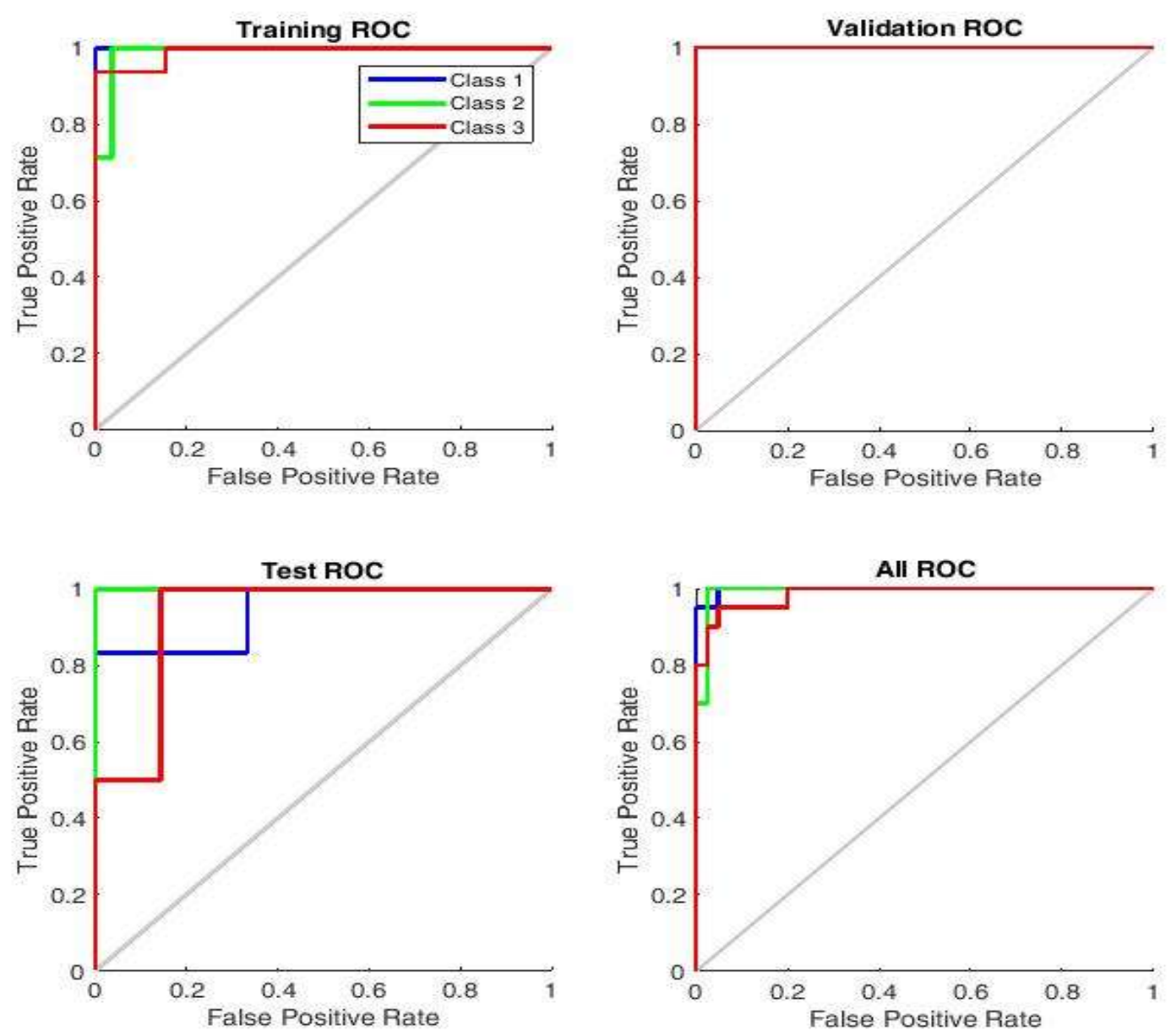

Figure 5: Receiving Operating Characteristics

In the receiving operating characteristics of the training samples, it shows a very good true positive rate. In the validation, a perfect positive rate and in the test sample a good positive rate is equally obtained signifying a good performance of the classifier. 


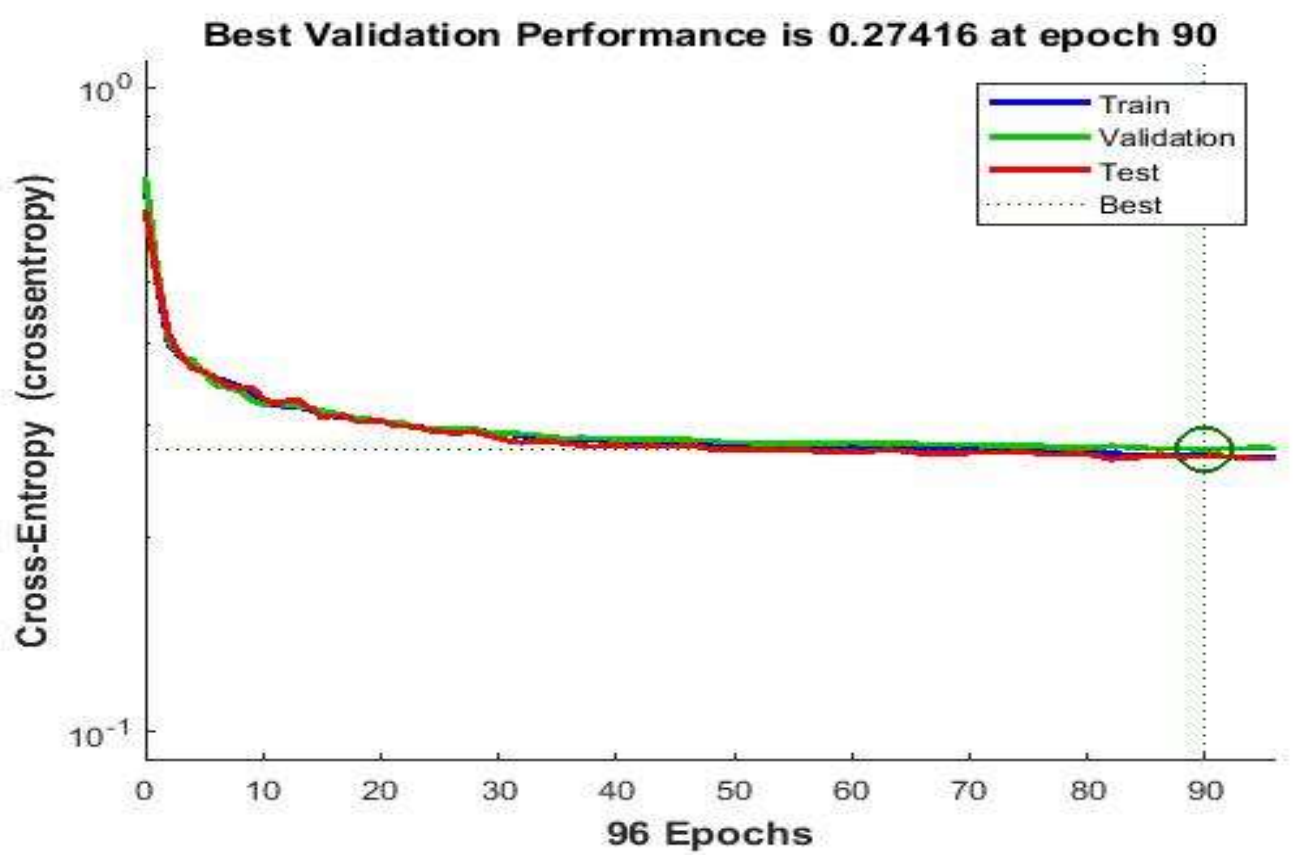

Figure 6: Network Validation Performance

In Figure 6, the performance of the network is very good as there is no problem of underfitting or overfitting of data. The best fit is below 1 indicate an excellent performance and the training, validation and testing are perfectly fitted and touch the best fit line at about 40 epochs and continue without separating up to the 90th epoch for the best validation performance at 0.274 which very good since it is below 0.5 .

\section{CONCLUSION}

In this research, NERICA-4 rice variety was cultivated on a piece of about $750 \mathrm{~m}^{2}$ land located at Kujama-Chikun Local Government Area of Kaduna State, Nigeria. The land was properly prepared for cultivation with good seeds at the early month of June, 2020. Proper weeding and right application of fertilizers were observed in order to obtain very good yield for the research. Sample images for classifications were obtained at different maturity periods labeled as late dough stage, yellowing stage, and ripening stage. The ripe stage represents the optimum maturity period. The images were preprocessed and processed to extract relevant features for classification using ANN. The result of the classification shows an overall performance of 93.30\% as seen in Figure 4 of the all confusion matrix. The all receiving operating characteristics also gave an encouraging result that indicates a good classifier. This results when made operational would reduce losses encountered during harvest by local farmers and improve the use of NERICA-4 rice variety plantation in uplands ecological region of sub-Sahara Africa, as it is the most desirable variety due to its deliciousness. This will improve productivity and wealth for the local farmer.

\section{Data Availability}

The NERICA-4 rice variety images used for this research are obtained from a farm land cultivated at Pamfura-Kujama in Chikun Local Government Area of Kaduna State and are available upon request.

\section{Conflict of Interest}

The author declares that there is no conflict of interest regarding the publication of this paper.

Acknowledgement

The author acknowledges the contribution of Zachariah Babangida of Computer Science Department, Kaduna State University, Kaduna, Nigeria for sharpening the outcome of this paper. Mention must be made of Mrs. Peter Rahila Ayuba of the department of Biological Sciences, Kaduna State University, Kaduna for the cultivation and management of the farm land.

\section{REFERENCES}

Food and Agricultural Organization of the United Nations (FAO), (2017). Production guide line for rice. First season-long training of trainers on integrated rice crop management under the national rice revitalization programme of the ministry agriculture. Technica Cooperation Programme with the Repulic of Fiji.

Kamai, N., Omoigue, L. O., Kamara, A. Y., \& Ekeleme, F. (2020). Guide to rice production in Northern Nigeria: Feed the future Nigeria integrated agriculture activity. International Institute of Tropical Agriculture (IITA), Ibadan, Nigeria, 27 pp.

Meena, B. P., Prasad, D., Dotaniya, M. L. \& Meena, V. D. 
(2014). Modern techniques of rice Production: A key for ecosystem sustainability in changing climate. Indian Farming, 64(3): 11-14.

Of, O., Mu, D., \& Okeke, M. N. (2018). Adoption of New Rice for Africa (NERICA) technologies in Ekiti State, Nigeria. African Journal of Food, Agriculture, Nutrition and Development, 18(3):13617-13633.

Oikeh, S. O., Nwilene, F. E., Agunbiade, T. A., Oladimeji, O., Ajayi, O., Semon, M., Samejima, H. (n. d.). Growing upland rice: a production handbook. African Rice Center (WARDA). Retrieved from www.warda.org

Oli, P. (2018). Rice growing guide. Retrieved from Researchgate.net/publication/328980021

Peter, A., Abdulkadir, S., \& Abdulhamid, U. F. (2017). Detection of optimum maturity of maize using image processing and artificial neural networks. Science World Journal, 12(2): 24 27.

Peter, A., Damuut, L. P., \& Abdulkadir, S. (2020). Determining the optimum maturity of maize using computional intelligence techniques. American Journal of Neural Networks and Applications, 6(1):1-9.

Peter, A., Damuut, L. P., \& Abdulkadir, S. (2020). Improved determination of the optimum maturity of maize based on Alexnet. Science World Journal, 15(3):133-138.

Troldahl, D. (Ed.). (2018). Rice growing guide. State of NSW through department of industry, skills and regional development. NSW Department of Primary Industries. Retrieved from https://www. Researchgate.net/publication/328980021

Rodenburg, J., Diagne, A., Oikeh, S., Futakuchi, K., Kormawa, P. M., Semon, M. ... Keya, S. O. (n.d.). Achievements and impact of NERICA on sustainable rice production in sub-Sahara Africa. Regiona perspectives. Retrieved from https://www. Researchgate.net/publication/

Shinya, Y., Kosaki, M., Inoue, K., Koimaru, M. T., \& Sokei, Y. (2011). Guide for NERICA cultivation. Training on production and extension of NERICA. Retrieved from www.jica.go.jp

C2021 This is an Open Access article distributed under the terms of the Creative Commons Attribution 4.0 International license viewed via https://creativecommons.org/licenses/by/4.0/ which permits unrestricted use, distribution, and reproduction in any medium, provided the original work is cited appropriately. 